\title{
For the Greater Good? -A Critical Reflection on Assessing Indirect Economic Effects Caused by Large Transport Projects
}

\author{
Delphine $^{1 *}$, Patrick Witte ${ }^{1}$, Thomas Hartmann ${ }^{2}$, Tejo Spit ${ }^{1}$, Annelies Zoomers ${ }^{1}$ \\ ${ }^{1}$ Department of Human Geography and Planning, Utrecht University, Utrecht, The Netherlands \\ ${ }^{2}$ Faculty of Environmental Sciences, Wageningen University and Research, Wageningen, The Netherlands \\ Email:*d.delphine@uu.nl
}

How to cite this paper: Delphine, Witte, P., Hartmann, T., Spit, T. and Zoomers, A. (2019) For the Greater Good?-A Critical Reflection on Assessing Indirect Economic Effects Caused by Large Transport Projects. Open Journal of Civil Engineering, 9, 135-156. https://doi.org/10.4236/ojce.2019.92010

Received: May 5, 2019

Accepted: June 8, 2019

Published: June 11, 2019

Copyright $\odot 2019$ by author(s) and Scientific Research Publishing Inc. This work is licensed under the Creative Commons Attribution International License (CC BY 4.0).

http://creativecommons.org/licenses/by/4.0/

\section{c) (i) Open Access}

\begin{abstract}
Investing in large transport projects affects the (potential) economic development of metropolitan areas. Yet, very little critical research has been performed to understand how to assess these effects. The relationship between infrastructure investments and regional economic development is complex and indirect, and many theoretical and methodological difficulties remain. On the one hand, the assumption that investing in infrastructure is important to sustain economic growth is sometimes doubted. On the other hand, it is argued that investments in infrastructure enhance the accessibility of urban regions and that in the slipstream of such investments, social problems in urban regions can be tackled as well. Despite these contrasting views, there is at least a consensus that transport infrastructure development depends on economic development and vice versa. Yet, in many cases, the method of assessing economic impacts highly affects the results. Therefore, this paper focuses on a critical reflection of methods for estimating economic effects of infrastructure investments. A critical evaluation is made based on Indonesian and Japanese cases. After conducting in-depth desk research on both cases, we found that the broader effects on affected group of people tend to be overlooked due to the problems of time and space dimensions, the chain reaction of effects, and inappropriate data practices. The assessment on the appraisal processes tends to overlook the broader economic implication due to narrow focus and the concept of efficiency of economic theory.
\end{abstract}

\section{Keywords}

Large Infrastructure Projects, High-Speed Railways, Economic Effects,

Transport Investment, Economic Assessment 


\section{Introduction}

For the last decade, the proponents of large infrastructure projects tend to structurally oversell the magnitude of growth effects [1]. A large scale project is usually associated with big money, long duration, numerous stakeholders, poor performance records, enormous resource use, inherent risk, complexity, and uncertainties [2]. It is sometimes perceived as a magical strategy to achieve greater economic growth by the project proponents in an over-optimistic way (see [1]). However, the relationship between large infrastructure project investments and economic growth is indirect and questionable. Some studies show that investing in large-scale infrastructure affects (potential) economic development [3] [4] [5]. However, the economic effects are different among projects in terms of direction and magnitude [6]. Thus, a common understanding of the indirect effects is hard to achieve.

There are two major problems. First, the effects of large infrastructure projects are interrelated. In terms of service improvement, investments awaken diverse interconnected economy-wide processes and benefit a set of sectoral, spatial, and regional impacts, increasing productivity as a whole [7]. However, due to contested nature of the information supply, the process of generating information has led to the negotiated knowledge rather than objective knowledge [8]. Thus, there is a tendency to misunderstand these effects due to spatial multiplier effects and possible specification biases [9]. Second, the planning stages consist of complex uncertainties. In the decision-making process, different opinions among policy-makers about budget allocation tend to frustrate the process. This is mainly because large scale investments raise risk and uncertainty in dealing with design, construction, and funding [10]. Later, the frustration effects unsurprisingly contribute to political discussions-regarding volume and location of the projects-to generate as many indirect economic effects as possible. Unfortunately, these effects are hard to predict.

Because of these problems, a common understanding of the indirect economic effects of infrastructure development is important. However, very little critical and empirical research has been performed concerning how these effects can be assessed (see [11]). Therefore, this paper aims to provide a critical reflection on assessing indirect effects of large scale transport projects appraisal. This is important because politicians are captivated by large scale, and any analysis during the development processes could easily be manipulated and thus needs to be standardized [12].

The next section outlines the assessment methods. First, the identification of different effects is presented along with the methods. Second, to challenge these methods, theoretical and methodological pitfalls are demonstrated. Further, empirical insight on an Indonesian case is presented. As a comparison, a Japanese case experience is briefly described. Finally, some concluding remarks, as a reflection, will give recommendations for future research. 


\section{2. (Indirect) Economic Effects and the Method of Estimation}

To begin with, a set of assessments determines the conditions in which infrastructure investment can influence economic effects. In Europe, for instance, appraisal is depicted as a tool providing relevant information to decision-makers and is used in the process of planning transport systems [13]. However, in the early phases, the information is limited and mainly biased and judgemental [14]. It is also difficult to determine the causality between transport investment and economic growth, as the relationship is indirect and complex, and gets more complex as the investigation expands.

Therefore aiming at better orientation in all of impacts caused by the large scale infrastructure project, this section classifies the effects of large infrastructure projects based on the combination of the types (direct vs. indirect) and the time period of these effects (temporary vs. permanent), especially in case of transport project. The categories are adapted from the Economic Effects on Infrastructure-Overzicht Effecten Infrastructuur (OEI) - method that acts as a guideline in transport infrastructure in the Netherlands to monetize the effects of development. This guideline groups the effects into four classifications: direct temporary, direct permanent, indirect permanent, and indirect temporary effects (see [15]). The discussion focuses on the first three types of effects due to rare evidence of indirect-temporary effects.

In the following sub-section, the explanation regarding the current methods used for the assessment is presented. The explanation itself will be divided into three parts based on the types and time period of the effects. Then, the discussion continues about theoretical and methodological pitfalls and follows a framework of interrelated processes in assessing economic effects of infrastructure investment.

\subsection{Diverse Effects of Transport-Infrastructure Investments}

First, the effects are divided into direct and indirect effects. For transportation development, direct effects are associated with the effects on behavioural choices of users, while indirect effects are determined by the effects outside the transport market resulting from new infrastructure [16]. The difference is in where the jurisdiction of the effects takes place [17]. Thus, there is a dimension of space where the effects take place, whether inside or outside the market of development. Furthermore, indirect effects relate to a wider scope, such as accessibility or area competitiveness. Because the indirect effects usually occur in the long run, the planning stage debates about the priority of investments mostly occur between politicians. The debate emerges from the existence of numerous stakeholders with various perspectives, conflicting interests, and a certain degree of uncertainty [18]. At the planning stage, it is highly important to gain a common understanding about the effects. Different perceptions might lead to rejection from a particular group of stakeholders. This may be because the benefits might only relate to certain groups, while other groups pay for the disadvantages or 
externalities.

Second, based on the time in which the effects occur, they are categorized into temporary and permanent effects. Temporary effects occur during the construction period, while permanent effects occur within the usage stage [19]. In this sense, temporary effects are usually related to the costs of construction itself, such as jobs derived from the construction. Permanent effects deal with the longer presence of particular transportation projects. The shape of the effects ranges from simply reducing travel time to restructuring the spatial arrangement. The time dimension plays a significant role in determining the effects, especially to create sustainable projects (e.g. [20]). Taking the time dimension into consideration, the division of effects differentiates three development stages: planning, construction, and usage. Each stage has its own characteristics and time period of effects. The assessment at each stage of project development is crucial to see the causal relationship between planned effects and actual outcomes [21].

The difference between the effects can be seen on Figure 1 and the following sub-chapters.

\subsubsection{Direct-Temporary Effects}

The planning and construction stage is where the building cost and employment effects mainly occur. Although in practice these two effects also appear at the construction stage, their influence can be considered marginal-compared to the total investment-and too dependent on other factors to be analysed separately. At the construction stage, a "quick scan" method is developed to assess the effects. This method is usually an initial scan evaluation [22]. The advantage is that this simple method only requires a minimum amount of data. The costs are calculated per kilometre based on the type of infrastructure and a limited number of other basic characteristics. Standardized construction cost indicators are developed for each type of infrastructure, along with percentages for works of art and some physical construction. The precise calculation is necessary if the ground plan is known.

Acquisition of land and removal of existing structures can then be added to the calculation (see e.g. [23]). Employment effects are considered directly related

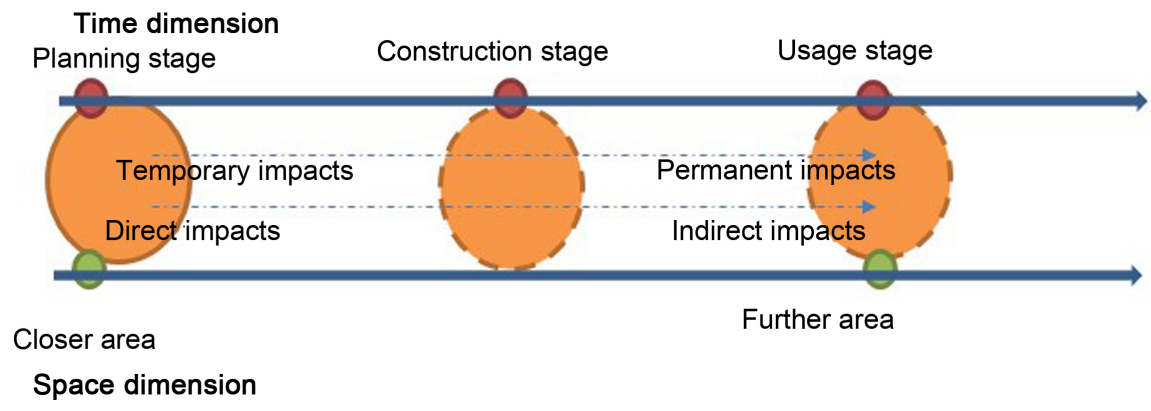

Figure 1. Diverse effects of transport infrastructure investment. 
to the volume of the investment. The employment indication seems to work adequately in practice. Some projects are intended to increase construction employment (e.g. [24]). These effects are substantial, although by nature they are temporary.

\subsubsection{Direct-Permanent Effects}

The general measurement of transport projects is highly related to improve travel and the relative attainability of certain areas. The first effect to assess is travel time and cost-effectiveness. To determine these effects, it requires some traffic model data, namely, traffic flows, travelling times, and distances before and after the investment. The data is gathered from the observation of personal travel behaviour in a week to see the general pattern. Then, certain indicators are used to monetize the expected effects. In practice, there are two approaches to assess the valuation of travel time. They are revealed preference and stated preference. While revealed preference deals with alternative choices, the stated preference involves the hypothetical choice of routes and modes [25]. Stated preference is more common than revealed preference when analysing the value of travel time savings (VTTS). Due to shorter data collection time, a response to a new modal or route choice will be given by passengers of firms [26].

The next effect is the change in travel behaviour. Naturally, passengers will respond to the new infrastructure. The first response would be route change, journey re-arrangement, new destination choice, increased travel frequency, new journey generation and land use pattern change [27]. On this basis, people are free to make a "choice" regarding their travel behaviour as new modes have been developed. Travel, then, is not the purpose of the activities but instead a means to achieve such activities [28].

To assess the trend, a strong emphasis on the sets of data used as an input for assessing self-reflection is necessary [29]. The data includes socio-economic variables, such as sex, age, household and income. With this data, multilevel regression models or structural equation modelling (SEM) can be used to estimate the direct effects of person or household variables on travel behaviour and on location choice, along with the impact of land use variables on travel behaviour.

The change in travel behaviour creates new activities, such as new commuters' activities. Sooner or later, this mass flow of people will somehow make some spatial intervention in a particular area. The new activity pattern will be generated along the corridor of people movement. Travel behavior in general shapes the repetition of activities and there is a strong relationship in travel behaviour between spatial patterns and repetitive use of activity locations over time [30].

\subsubsection{Indirect-Permanent Effects}

Indirect-permanent effects relate to induced effects and to the backward expenditure effects of the exploitation of infrastructure [19]. In the long term, it is expected that transport investment policy will enhance the accessibility of a particular area. Accessibility can be defined as "the measure of the capacity of a lo- 
cation to be reached by, or to reach [a] different location" ([31], p. 322) related to good spatial interaction, potential connected activities or goods, attractive nodes in a network, and the travel costs to and from the node [32]. Some simply express accessibility with traveling speed as a measure. But, in a more complex form, regional accessibility could be determined using Newton's law of gravitation as a function of regional attractiveness and transport cost (see [33]).

Besides accessibility, the indirect effect of labour supply and product expansion is also of relevance. Some might argue that the added value from job creation is considered marginal and could be assessed simply by the "quick scan method" as discussed before. However, transport investment in the area changes the effective density of people as well as the jobs, which affects productivity and effectiveness [34]. When a particular area has easy access, firms or businesses prefer locations with a high quality infrastructure. Sufficient public transport appears to be a crucial factor for locating firms, especially for larger intra-regional firms [35]. The rationale behind this is that a high quality infrastructure can decrease the traveling time of individual passengers and reduce the transportation costs for industrial freights [36]. The lower the transportation cost, the more the industry will invest. Consequently, there will be a change in travel behaviour of freights or passengers, leading to spatial intervention regarding the flow of people and goods. In this sense, the proliferation of industry calls for a high number of labourers and high-quality employees.

Taking a broader perspective, the effects of labour supply will lead to agglomeration. Infrastructure durability plus labour supply lead to new agglomerations in urban areas [37]. If two or more agglomerations occur in a certain area, they will intensify the re-arrangement of the spatial pattern of this area. The structuring effect of this arrangement is twofold. First, it generates new traffic and enhances economic performance by improving area attainability and transport reliability. Second, it develops possible adjustments of particular economic activities. The regional real estate market, for example, will benefit from the infrastructure improvement, followed by stimulating housing markets and commercial real estates.

Lastly, competitiveness occurs when at least two firms connect and relate to each other as competitors within a complex network of interactions [38]. This could happen if the ease of regional activity has invited too many firms to invest. The area becomes more competitive and then tends to enhance the economy and increase the overall GDP.

\subsection{Pitfalls in Achieving the Greater Good: A Reflection on Large Transport Project Assessment}

Although in fact the effects of transport infrastructure are diverse and occur dependently on time and space as shown on the previous section, a systematic approach to measuring the impacts of large sale transportation projects cannot be considered fully successful. In taking effects into consideration, some pitfalls 
range from sectoral perspectives, to incorporation of wider strategic issues in the economic cases [39]. A complex planning case such as a transportation project is usually followed by fragmented smaller assessment approaches [40]. In large transportation project assessments, the pitfalls are divided into theoretical pitfalls and methodological or practical implications.

\subsubsection{Theoretical Pitfalls}

Decision-making tools such as the CBA are sometimes misused, because it is difficult to technically quantify relevant values of equity, dignity, or fair distribution [41]. When measuring the indirect effects of large scale transport projects, it is hard to fully predict actual effects due to the uncertainty of future events. As a result, the assumptions in the assessment play a significant role in drawing up the effects. However, the definition and scope of projects is often influenced by political motives. As a result, ambiguity arises on practices that have an appraisal regime that is influenced by political systems [42] and may cause the assessment to be misused. There are four reasons for misused decision-making tools, as presented below. To explain the theoretical pitfalls, this paper proposes a framework, as shown in Figure 2. The pitfalls regarding the assessment methods relate to the following: 1) time dimension, 2) space dimension, 3) chain reaction of effects, and 4) strategic dimension (Figure 2). Because the processes are interrelated, these four pitfalls should be considered in the indirect economic effects assessment on large scale projects.

First, the time dimension becomes crucial in the analysis due to the temporary and permanent effects of the projects as well as the different characteristics of effects occurring on each stage. In the short term, the costs of infrastructure development are relatively high, including all inconveniences and NIMBY behaviour on the development stage. Yet, the net benefit tends to be negative for a time, then turns to be positive [43]. The time dimension also becomes crucial,

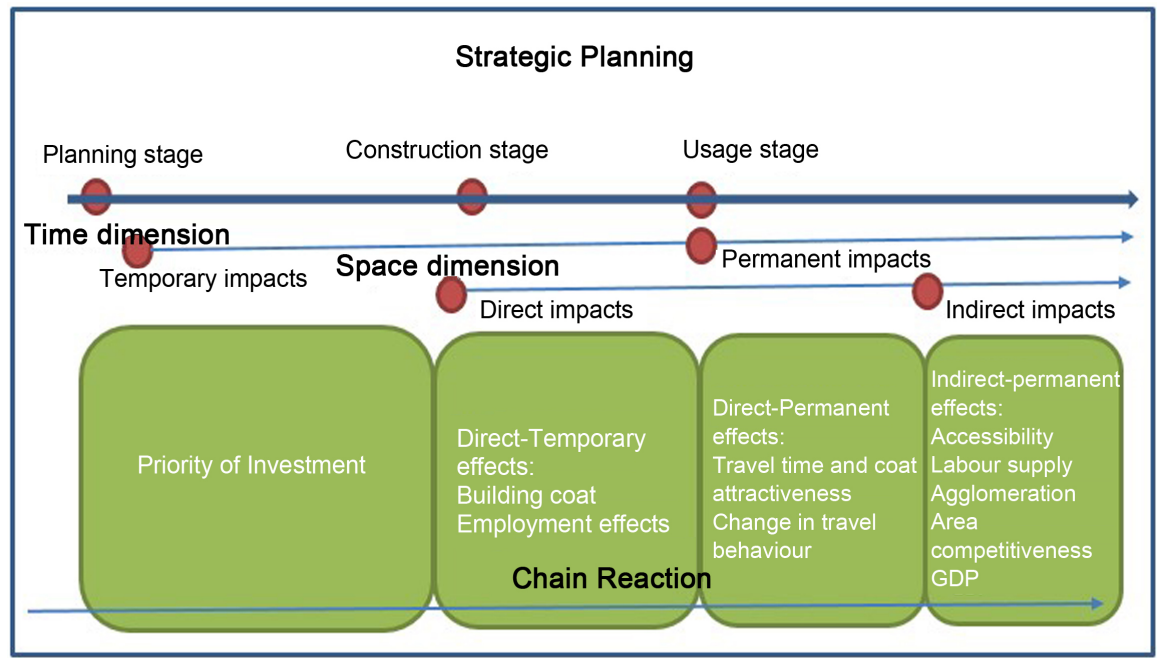

Figure 2. Interrelated processes in assessing economic effects of infrastructure investments. 
especially from an economic perspective, because the impacts evolve overtime. However, the current assessing methods, CBA, do not estimate the Residual Value adequately [44].

Also, over a long period, the distinctions between public and private investments and how public and private actors correspond with the investments are necessary. It seems biased to assume that the investment on public goods will give a similar rate of return as the private investment. During the long run investments, the return rate behaviour might differ due to the uncertainty of future events. Public goods do not usually take "making money" as the central core of investment purposes. The profit is small and usually occurs over a long period of time [45].

Second, the space dimension is important in the analysis, as the direct and indirect effects of the projects deal with jurisdiction of the transport market. Transport plays an important role in spatial relations between two or more locations [31]. Therefore, the spatial re-arrangement follows the importance of space in the project development's effects. For example, accessibility cannot be assessed as one entity, because it evolves as a mutual correlation from one area to another. The interdependency of two or more areas creates a viable economic activity. Thus, the improvement in regional accessibility might open new opportunities for economic development as a side effect of decreasing transport time and increased travel cost effectiveness. The flow of people benefitting will generate other new infrastructure developments surrounding the project, creating a new spatial structure to support in a network.

Third, there is a sensitivity implied by the change in transport systems. A simple change in a transport system might lead to larger effects, the chain reaction. Change in travel behaviour, for example, might intervene in the spatial arrangement of a city or area. Although modelling aims to find the key links between causes and effects, the models are mainly designed to be descriptive [46]. The assessment of each effect is performed as a single modelling. Even worse: "Causality was seen as less relevant than forecasting performance" ([46]; p. 6). For example, although recent studies involve land, and consumer and firm location, they do not deal with the relative choice of location. This choice is fundamental in the economic analysis of an infrastructure project's appraisal [38].

Fourth, spatial re-arrangement is organized on the public question of whether the development of infrastructure projects will attract economic activities or cause a relocation of existing spatial arrangement. The spatial re-arrangements will also affect different spatial scales since transportation projects are usually interconnected with the need for strategic planning. The distinction between (inter)national, regional, and local levels that are working within administrative boundaries is not sufficient to explain the complexity of transportation systems across boundaries. Investment in infrastructure should be seen by decision and policy makers as investments in a wide range of modalities to secure the interconnectedness of the system with spatial, economic, and institutional contexts, 
instead of just a single infrastructure. However, the literature has overlooked functions of the broader sustainability criteria in large projects' evaluation [47].

\subsubsection{Methodological and Practical Implications}

In practice, the assessments described in the framework above often meet methodological and practical difficulties. The first methodological problem deals with the existence of primary and secondary data. For instance, in the stated preference approach, the actual data of passengers or a firm's response to new infrastructure rarely exists; the hypothetical situation of the stated preference relies heavily on the data gained, but only if the context of the situation is carefully defined and framed [26]. Not only does the existence of relevant data matter, but also the comparability of the data. Comparable data must meet the requirements of time and space relevancies. The projection of data for the longer run is crucial as well for different spatial levels. Particular data usually only represents the moment the data is gathered. Further, variation in analytical methods is cumbersome. To give a comprehensive analysis, the assessment tools should be related to one another. The availability of secondary data analysis has a wide range of methods due to different disciplines being used for underlying assumptions. While the secondary data faces this problem, the primary data is also not favourable because it is expensive [48]. Lastly, the problem deals with the singularity of the case. Investing in a transport project means investing in modality that is unique in terms of quality and spatial, economic, and institutional contexts. This uniqueness tends to complicate comparisons between case studies.

Although the problems mentioned are persistent, this does not mean that research on the economic impacts of large infrastructure projects is pointless. The upcoming projects still need to be assessed.

\section{Indonesian and Japanese Experiences with Large Transport Projects}

On the following section, we present the empirical case that shows whether the assessment on the appraisal have fully covered the variation of the effects. The case study of Indonesian high speed railways at the early planning stage is presented to analyse the economic effects illustrated on feasibility study, meanwhile the Japanese case at the usage stage is presented to depict the actual effects of the investment.

\subsection{Case Study Description and Methodology}

There is a flourishing trend of Asian large infrastructure project development which is currently led by the Japanese, Korean, Taiwanese, and Chinese construction industries [49]. Although large infrastructure projects are slowly but surely becoming common practice, many people still try to figure out the most appropriate way to depict the economic benefits as a reason to promote a particular project. Because of the wide experience with large scale development in an 
Asian context, it might be useful to distil some lessons from Asian practice dealing with the economic assessments. Therefore, in the upcoming paragraphs, this paper will provide greater insight into Indonesian and Japanese planning practices.

Indonesia, as the fourth most populous country in the world, has the potential to affect economic competitiveness world-wide. The long-run targets written on Mid-term National Development Plan 2015-2019 showing Indonesia as becoming one of the top ten economies, has been officially legalized. To meet this goal, Indonesia started the development of high-speed railways. The first route will connect the Greater Jakarta Metropolitan Area and Bandung Metropolitan Area and will be expanded to Surabaya Metropolitan Area by means of the Java Economic Corridor (Figure 3). The total investment is 2000 trillion IDR, which equals 133 billion Euros [50]. This project seems to be the biggest ambition of transport infrastructure development in Indonesia to date. Developing large scale transport projects has become a new entity of Indonesian planning practice, although it is not without its problems in assessing the potential effects. Some of them have failed to meet the expected goals and left out the effects regarding particular groups of people (e.g. [51] [52]). Therefore, it is interesting to take the first phase of Indonesian high-speed railways as a case study due to its highly substantial cost. This paper will show the interrelated processes in the economic assessment of this case study and how the assessment gives a picture of future events at the early planning stage.

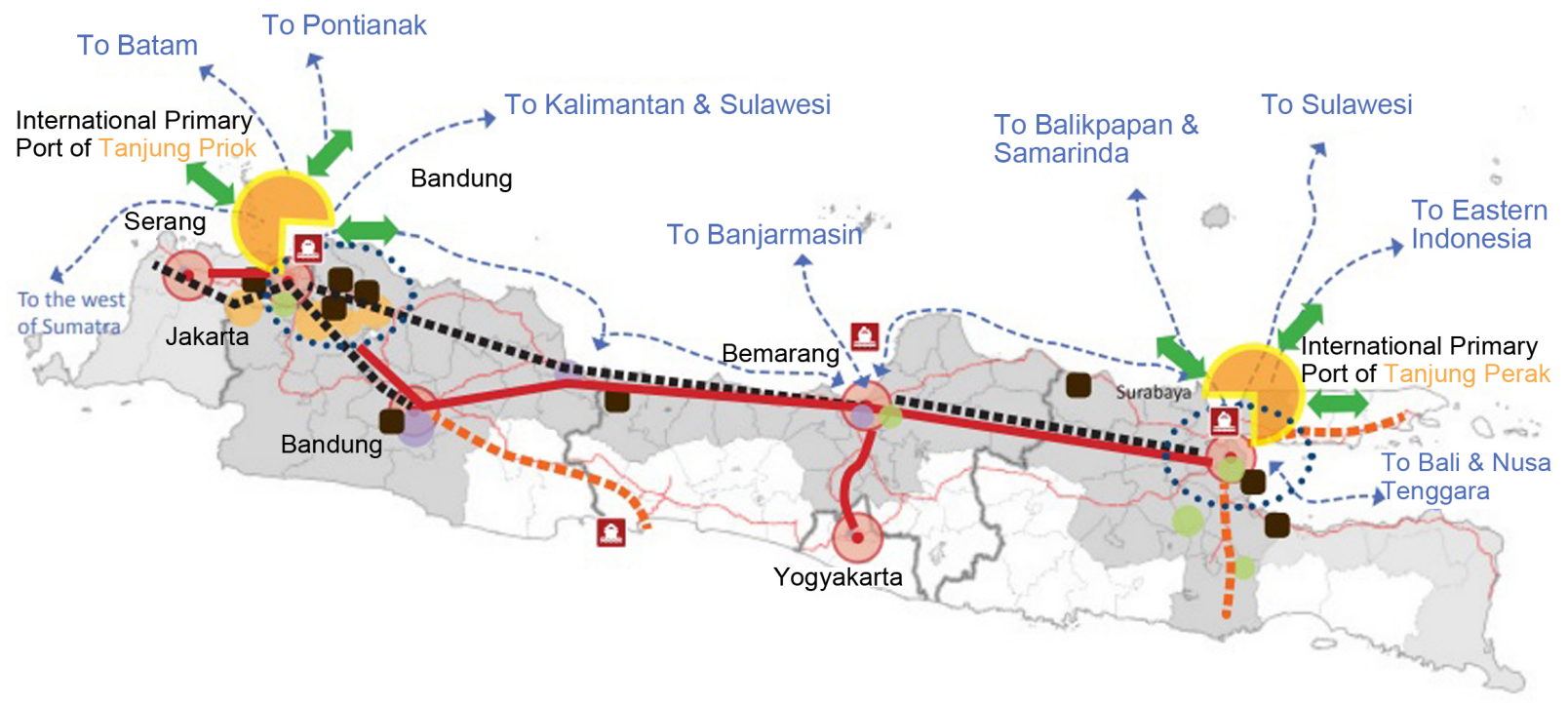

- Capital City/Economics Center O Industrial Cluster

Food and Beverage Industry Node Textile Industry Node

Manufacturing Machinery and $= \pm=$ Main Exit Corridor Lane Transportation Equipment Node $-\rightarrow$ Domestic Sailing Network

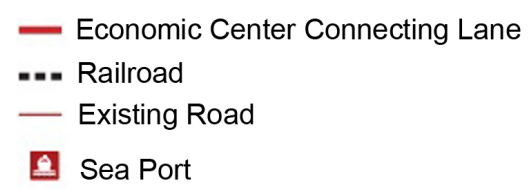

- Economic Center Connecting Lane

- Existing Road

A Sea Port

Figure 3. Java economic corridor. Source: [50]. 
On the other hand, Japan's high-speed railway Shinkansen is chosen as a case study because its success is well-known worldwide after operating for more than half a century. The Tokaido Shinkansen proved to be an effective and reliable means of high-speed transportation leading to a new trend of high-speed railway development worldwide, such as in Germany, China, Korea, and France. While the first case shows the assessment at the early planning stages, the second case will act as a comparison in seeing the actual outcome of a project at the usage stage. Besides its expertise on high-speed Railways, the Japanese case study is selected because in the first phase assessment of the Indonesian high-speed railways (used for this research) Shinkansen is used as a comparison.

In both cases, in-depth desk research will be performed. For the Indonesian case, the "Feasibility Study on the High-Speed Railways Project (Jakarta-Bandung Section) November 2012" prepared by Japan International Consultants for Transportation (JIC) for Japan Ministry of Economy, Trade and Industry is used as secondary data to illustrate how economic effects of this project are assessed in practice. For the Japanese case, the analysis will be generated based on previous studies that have been done by various scholars about Shinkansen.

Then, both cases will be presented in a narrative, descriptive way. The framework from the theoretical part (see Figure 2) will be used to structure the discussion about the effects assessed from the case studies, and the lessons learned from both cases will be given.

\subsection{High-Speed Railway Development in Indonesia}

The feasibility study examines three different routes (see Figure 4), and examines the alternatives based on three points of view: technical, demand, and financial.

The first direct economic effect assessed in the study is the priority of investment. The urgency of the project is based on the need to break up the less

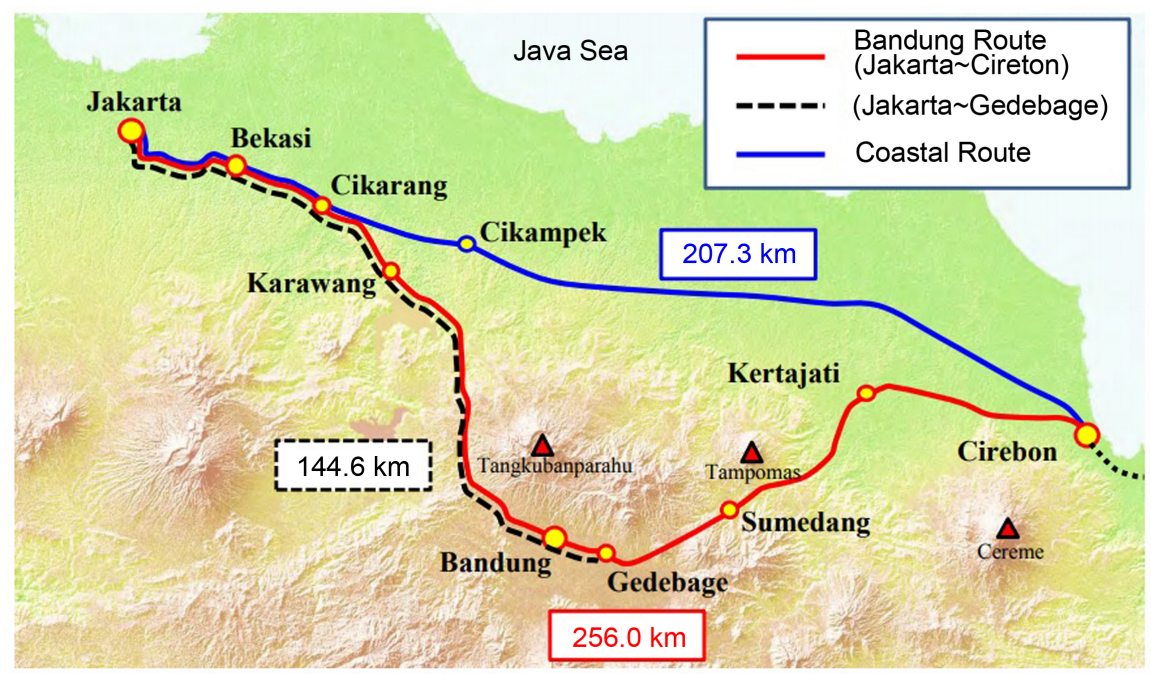

Figure 4. Comparison between Bandung route and coastal route. Source: [53]. 
competitive existing conventional railway services to support the intercity connection along Java Island. Moreover, the National Railway Master Plan put a strong emphasis on the necessity of the high-speed railways to boost the economy. However, in 2008, the examination of Jakarta-Surabaya high-speed railways showed that the project cost was up to 2.1 trillion JPY or equal to 17 billion Eu$\operatorname{ros}[53]$.

Second, in terms of building costs, it is estimated that between the three alternatives, the lowest cost goes to Jakarta-Cirebon (Coastal Route) with only 2818 million JPY or equal to 22 million Euro per km, followed by Jakarta-Bandung-Cirebon and Jakarta Bandung Gedebage, which are respectively 2837 million JPY (22 million Euro) and 3427 million JPY (27 million Euro). These numbers include construction costs for rolling stock, project implementation cost, as well as land acquisition cost. To minimize the building cost, the land acquisition budget is reduced by utilizing the toll roads and conventional railways area. The crossings with urban areas, firms, commercial facilities, graves, mosques, and other public facilities should be avoided along the route choices. In the Jakarta Metropolitan area, the route will be underground as this area has already been well developed above the ground in terms of infrastructure, high-density real estate development, and so on.

The third economic impact is travel time and cost attractiveness and change in travel behaviour. In terms of travel time, the feasibility study shows the acceptability and willingness of prospective users to pay, and the conversion ratio from existing models. From this feasibility study, comparison of traveling time is presented on Table 1 below.

Further, the change in travel behaviour is estimated through a binary logit model and demand forecasting. It is argued in the study that the demand for the Bandung route is almost four times larger than that of the Coastal Route by the year 2050.

Besides the direct effects, the broader economic effects and financial feasibility are assessed through the Economic Internal Rate of Return (EIRR) and a CBA (see Table 2). Both approaches describe the Bandung Route as more feasible. The comparison of costs and benefits between the Bandung Route and the

Table 1. Comparison of travel time. Source: [53].

\begin{tabular}{|c|c|c|}
\hline Transportation Mode & Jakarta-Bandung & Jakarta-Cirebon \\
\hline Conventional Railway & 3 hours & 3 hours \\
\hline Passenger Car & 2 hours & 5 hours \\
\hline Long-Distance Bus & 2 hours & 6 hours \\
\hline Bandung Route & 37 minutes & 70 minutes \\
\hline $\begin{array}{l}\text { High-Speed } \\
\text { Railways }\end{array}$ & $\begin{array}{l}118 \text { minutes } \\
\text { (Change to existing railway } \\
\text { at Cikampek) }\end{array}$ & 49 minutes \\
\hline
\end{tabular}


Table 2. Result of economic and financial analysis. Source: [53].

\begin{tabular}{|c|c|c|c|c|}
\hline \multirow{2}{*}{\multicolumn{2}{|c|}{ Index }} & \multicolumn{2}{|c|}{ Bandung Route } & \multirow{2}{*}{$\begin{array}{c}\text { Coastal Route } \\
\text { Jakarta-Cirebon }\end{array}$} \\
\hline & & Jakarta-Bandung-Cirebon & Jakarta-Bandung-Gedebage & \\
\hline & $\mathrm{B} / \mathrm{C}$ & 1.30 & 1.91 & 0.11 \\
\hline & EIRR & $13.6 \%$ & $16.2 \%$ & Negative \\
\hline ENP & V (JPY million) & 127,295 & 260,079 & Negative \\
\hline & BOT (AF 50\%) & $8.5 \%$ & $8.6 \%$ & $4.9 \%$ \\
\hline \multirow[t]{2}{*}{ FIRR } & $\begin{array}{l}\text { Concession } \\
\text { (Gove-S 50\%) }\end{array}$ & $8.4 \%$ & $8.6 \%$ & $2.3 \%$ \\
\hline & DBL (LC 1.4\%) & $15.5 \%$ & $15.8 \%$ & Negative \\
\hline
\end{tabular}

T: Build-Operate-Transfer, AF: Availability Fee, Gov-S: Government Support, DBL: Design-Build-Lease, LC: Lease Cost. ${ }^{*}$ Initial cost excluding rolling stock and station (11\% of total project cost) burdened by the private sector.

Coastal Route indicates a wide gap, 1.91 and 0.11 respectively. Even worse, for the EIRR, the Coastal Route shows a negative number. From this figure, the study seems to prefer the Bandung Route to the Coastal Route as explicitly stated in the study: "These figures proved that the Bandung Route has an advantage over the Coastal Route and that the construction of high-speed railways in the Bandung Route will be beneficial for the national economy" (pp. 11-12).

In terms of accessibility, the route selection of each alternative focuses on the connectivity of the new area. From a technical point of view, the selection of routes is assessed through the geographical conditions from the site survey. Later, consideration is given to choosing the shortest distance between stations, and the rationality of the location is determined by developing a new station in the suburbs and surrounding areas. In addition, since the Indonesian government has an agenda of airport expansion, the issue of integrated transportation systems between high-speed trains and the aviation industry will also be included in the study.

Surprisingly, the elaboration of other indirect permanent effects is not well developed in the assessment. Placing high-speed railways on a broad spatial scale without considering the broader economic effects is considered troublesome because it tends to exclude consideration of the people affected. This is a concern of the framework in Figure 2, taking as broad as possible the economic effects on the assessment of large scale projects.

\subsection{High-Speed Rail in Japan: Lessons from 50 Years of Shinkansen}

Investment priority discourse on the high-speed rail network of Japan started in 1930 when speed was highly important for the Imperial Expansion of Japan [54]. With four main islands stretching for about $3000 \mathrm{~km}$, Japan needed a reliable and fast transportation infrastructure to carry mass people and freight. At the time, the airplane was in its infancy, so a fast train was the only option. There- 
fore, the first train was built to open the accessibility of Tokyo, which was an isolated capital city. In 1964, the Tokaido Shinkansen started operating. Since then, Shinkansen has carried more than 7.6 billion passengers [54].

The building costs of the Shinkansen add up to 380 billion JPY or equal to 3 billion Euros. The travel time between Tokyo and Osaka has been reduced from 6.5 hours to 4 hours. In 1965, travel time decreased to 3 hours and 10 minutes at the speed of $210 \mathrm{~km} /$ hour [55]. Interestingly, Shinkansen saves up to 400 million hours per year, with $85 \%$ of passengers shifting their travel behaviour from conventional lines to high-speed railways [56]. This number was estimated by GDP per capita, and the value based on 2003 figures was equal to 500 billion JPY (3.9 billion Euros) per year [55]. Also, from 1969 to 1999, there was an increasing trend of ridership in Tokyo [55]. During this period, Japan's GDP also tripled; thus, the government believed that the development of Shinkansen contributed significantly to economic growth.

Shinkansen system has opened accessibility by opening a set of stations in smaller cities [55]. These stations often become the focal point of many urban developments. For example, there is a strong connection between Kakegawa City redevelopment and Tokaido Shinkansen development [56]. In addition, along Joetsu Shinkansen line, the station is some distance from where the city centre has been developed over the years. Shinkansen gives well-documented benefits for the regional economy, impacting 400 companies that are opening their branches along the Sanyo Shinkansen extension [54].

Despite these success stories, the impacts of high-speed railways on medium or intermediate cities are experienced differently. Intermediate cities on high-speed railway lines often experience job losses due to similar employment opportunities in corresponding regions. The smallest clusters like Kakegawa, Gifu-Hashima, Maibara and Atamu only gained slightly in employment opportunities [57]. There is only a slightly increasing opportunity for jobs in the small clusters like Kanagawa, with only $8 \%$ in the subsequent four years after the new Shinkansen station was built in 1988 [55]. This is mainly due to weakened economic roles of intermediate cities toward urban hierarchy [57]. However, the overall picture of new employment still seems promising. By reducing travel times and the introduction of private investments, jobs are created with the influx of new industries and businesses as well as added recreational demands in areas along the Shinkansen lines [55].

Later, the agglomeration patterns along the Shinkansen lines also show a significant change. Shinkansen impacts industrial locations in Japan, contributing to the regional economic structure, with new industries (such as real estate), businesses, and services [58]. Along the Tokaido lines, there are at least four different clusters created as an impact of the development of the Bullet Train [57]. They are: 1) world class finance and information business activities in Tokyo and Shinagawa stations; 2) secondary business and leisure service around Shin-Osaka, Nagoya and Kyoto stations; 3) important business clusters on the 
western edge of Tokyo, Shin-Yokohama station area and 4) small manufacturing and leisure services along Kakegawa, Gifu, Hashima, Maibara and Atami. In addition, Shinkansen influences the area competitiveness by inducing growth at the regional and local levels as well as increasing land values over time [59].

Further, these spatial redistributions might form the global competitiveness of the largest urban centres with the help of public policy guiding market shifts to station catchment areas [57]. For Tokaido Shinkansen, Japan's commercial redevelopment policy in Tokyo, Shinagawa and Nagoya affects the commercial land prices within $5 \mathrm{~km}$ of the Shinkansen stations [57]. Large-scale redevelopment projects through public-private partnerships flourish along this area. These policy responses guide the economic development induced by transport investment strategic planning, showing the direction of growth.

\subsection{Reflection from the Case Studies}

After the analysis, there are some interesting findings about how JIC conducted the feasibility study for the first phase of high speed railways in Indonesia compared to the Japanese Shinkansen. There are four reflections (see Figure 2) related to the theoretical pitfalls as discussed before.

First, dealing with time dimension, the effects are mostly derived from direct economic effects with only small consideration for the indirect effects. Taking Figure 2 as a framework, the feasibility study only covers five out of nine effects. They are the priority of investment, the building cost, travel time and cost attractiveness, change in travel behaviour, and accessibility. However, the broader effects are neglected (see Table 3 ). This is a result of simplifying the problem to quantify and understand the effects measured during the time frame of analysis [40]. Taking the Japanese case as an example, after being in operation for a half century, people can study both the direct and indirect impacts. Therefore, the consideration of the forecasting time frame is crucial. Even though the study from JIC already includes the demand forecast for the next 40 years, the definition of a future problem event is still rough in this case, especially as they conducted fragmented assessments for the different phases of development instead of taking the whole route from Jakarta to Surabaya.

Second, it is surprising that the feasibility study does not have an in-depth assessment regarding the space dimension in relation to the economy. The effects of infrastructure development, particularly transport infrastructure, should not be narrowed down to a specific area, but should be focused on the broader spatial level. Taking Shinkansen as a success story, after 50 years, the Japanese Bullet Train shows a remarkable effect on economic development, mostly on the metropolitan areas. For instance, industrial clusters of various types occurred as long-term permanent effects that could have led to a dispersed spatial structure if not handled properly. This is important to answer the challenge of multi-level appraisal in the decision-making process within national, regional, and local levels [42]. 
Table 3. Comparison of the consideration of effects between the case studies.

\begin{tabular}{|c|c|c|}
\hline Effects on Figure 2 & $\begin{array}{l}\text { First phase of Indonesian } \\
\text { High-Speed Railways, } \\
\text { Jakarta-Bandung }\end{array}$ & $\begin{array}{l}\text { Japanese Bullet Train, } \\
\text { Shinkansen }\end{array}$ \\
\hline $\begin{array}{l}\text { Priority of the } \\
\text { investment }\end{array}$ & $\begin{array}{l}\text { Improving existing } \\
\text { conventional railways service } \\
\text { to connect Java Economic } \\
\text { Corridor }\end{array}$ & Solution for "traffic hell" in 1950 \\
\hline $\begin{array}{l}\text { Building Cost and } \\
\text { Employment effects }\end{array}$ & $\begin{array}{l}\text { Construction cost: } \\
\text { approximately } 22 \text { million } \\
\text { Euros }\end{array}$ & $\begin{array}{l}\text { Construction cost of Tokaido line: } \\
\text { approximately } 3 \text { billion Euros }\end{array}$ \\
\hline $\begin{array}{l}\text { Travel time and cost } \\
\text { attractiveness }\end{array}$ & From 3 hours to 0.5 hours & $\begin{array}{l}\text { Tokaido-Osaka: from } 6.5 \text { hours to } \\
3.17 \text { hours }\end{array}$ \\
\hline $\begin{array}{l}\text { Change in travel } \\
\text { behaviour }\end{array}$ & Car and Bus move to Railways & $\begin{array}{l}85 \% \text { passengers from conventional } \\
\text { lines move to Shinkansen }\end{array}$ \\
\hline Accessibility & $\begin{array}{l}\text { Connectivity of new area and } \\
\text { connection of new airport. }\end{array}$ & $\begin{array}{l}\text { Opening accessibility of smaller } \\
\text { cities between Tokyo-Shin Osaka }\end{array}$ \\
\hline $\begin{array}{l}\text { Labour Supply and } \\
\text { Product Expansion }\end{array}$ & - & $\begin{array}{l}\text { Job losses in medium/intermediate } \\
\text { city, if any, only generate } 8 \% \\
\text { employment of Kanagawa district }\end{array}$ \\
\hline Agglomeration & - & 4 new clusters \\
\hline Area Competitiveness & - & $\begin{array}{l}\text { Inducing growth and } \\
\text { increasing land values through } \\
\text { policy guiding markets. }\end{array}$ \\
\hline GDP & - & Values: 3.9 billion Euros in 2003 \\
\hline
\end{tabular}

Third, although the assessment of the Indonesian high speed railways involves both qualitative and quantitative methodologies, the assessment of the chain reaction between each effect is still lacking. Each effect is treated as distinct and unrelated. For example, the study presents the demand forecasting of each route, but it does not imply the meaning behind such a number and how it will affect the wider economy. In addition, although the study implies a technical interconnectedness among different modes of transportation, the arrangement of intermodality in relation to economic effects is still ill-defined. The study of infrastructure should not be analysed per type of infrastructure but rather in the interrelations with each other. In which ways will the development of high-speed railways add economic value to the whole system?

Moreover, the most striking experience from the Japanese case stresses the need of policy intervention as a response to the investment itself. The objective of economic growth does not automatically happen even after substantial money has been invested. Policies regarding strategic planning have been developed to guide economic growth to positive overall outcomes of the investment [60]. These policies work on various levels from local to global level, as an overall strategic plan, but the investment itself is never enough. Therefore, the need for strategic planning that leads to a distinction between administrative levels is 
crucial to implement the strategic policies to support the investment for economic growth. The interconnectedness within each scale of transport system (local, regional, and national) must be the crucial part of the assessment.

\section{Conclusion and Discussion}

Based on two case studies, this paper has shown that although a set of appraisal tools has been used in the assessment of large transport projects, many theoretical and methodological difficulties remain. It is argued that the narrow attention given to the relationship between large transport project investments and economic effects needs to be broadened (e.g. [47] [60] [61]). In this paper, we have strongly argued that the consideration of the time and space dimension, the consideration of strategic planning, and the chain reaction issue are the keys to enhance appraisal tools and assessments and to determine the economic effects of the development (Figure 2). Because most economic effects are only considered in terms of indirect permanent effects, it is hard to quantify the real economic effects. Also, empirical evidence shows that the availability and comparability of data, as well as variation of the methods, remains problematic.

It is also central to questioning the equal distribution of the economic effects over the groups of affected stakeholders. Even though the assessment gives valuable information to decision-makers, the subjectivity of particular effects depends on the stakeholders who conduct the assessment. It seems that the social agenda sometimes lacks in the assessment of large transport projects. Even though the social impact assessment (SIA) might act as a tool to overcome this problem, this tool is not without its pitfalls. The transformational change of SIA practice is required, toward more valued end participation, rather than just being a means for project legitimation [62]. This is also in line with the argumentation of "It is not evaluation that depends on the values, rather the values that depend on the evaluation" ([63]; p. 77). The unequal distribution of effects, especially the social effects, highly depends on the value attached in the assessment.

In this case, it is hard to objectively measure the fairness or equity of certain policies because the concept of projects' values is highly subjective. There is a tendency to risk underestimation, in seeking to increase the project feasibility [64] [65]. Thus, instead of trying to explain this subject, the economic theory uses the concept of efficiency on each effect assessed [66] which provides a narrow focus on the effects. There is a need for integration of various dimensions of effects and better focus on scoping impact assessment [67]. The chain reaction of the effect of placing huge construction into certain areas cannot be explained through a narrow focus on assessments. Without considering broader effects, it tends to exclude significant effects of the development. Again, as a strategy to greater economic growth, large infrastructure projects can affect various groups of people differently in space and time. In some cases, the effects might be negative and become externalities for some groups of people, depending on the cir- 
cumstances and to who these values matter. A hardly-defined chain reaction among effects and the uncertainty of the trans-local effects are plausible reasons for this ambiguity. The process is not as easy as compensating the affected people and raises further questions in accommodating social agenda.

As an attempt to highlight this social agenda, it is recommended to conduct further research on how people become a central focus in any large scale project appraisal. There is a need to incorporate qualitative and quantitative approaches [68] as well as to cover broader socio-economic costs and benefits [69]. What does it imply for people in terms of time and space? With different perspectives about the effects, what does it imply for the political role of time and space?

\section{Acknowledgements}

This work was funded by the Indonesia Endowment Fund for Education (LPDP), Republic of Indonesia.

\section{Conflicts of Interest}

The authors declare no conflicts of interest regarding the publication of this paper.

\section{References}

[1] Flyvbjerg, B., Bruzelius, N. and Rothengatter, W. (2003) Megaprojects and Risk: An Anatomy of Ambition. Cambridge University Press, Cambridge. https://doi.org/10.1017/CBO9781107050891

[2] Oliomogbe, G. and Smith, N. (2013) Value in Megaprojects. Organization, Technology \& Management in Construction: An International Journal, 4, 617-624. https://doi.org/10.5592/otmcj.2012.3.5

[3] Yu, N., De Jong, M., Storm, S. and Mi, J. (2012) The Growth Impact of Transport Infrastructure Investment: A Regional Analysis for China (1978-2008). Policy and Society, 31, 25-38. https://doi.org/10.1016/j.polsoc.2012.01.004

[4] Lakshmanan, T.R. and Anderson, W.P. (2002) Transport Infrastructure, Freight Services Sector and Economic Growth. A White Paper for the US Department of Transportation, Washington DC.

[5] Summerhill, W.R. (2005) Big Social Savings in a Small Laggard Economy: Railroad-Led Growth in Brazil. The Journal of Economic History, 65, 72-102. https://doi.org/10.1017/S0022050705050035

[6] Vickerman, R.W. (2008) Cost Benefit Analysis and the Wider Economic Benefits from Mega-Projects. In: Flyvbjerg, B., et al., Eds., Decision-Making on Mega-Projects. Cost-Benefit Analysis, Planning and Innovation, Edward Elgar Publishing Inc., Northampton, 352.

[7] Lakshmanan, T.R. (2007) The Wider Economic Benefits of Transportation. Joint Transport Research, OECD and International Transport Forum.

[8] De Bruijn, H. and Leijten, M. (2007) Megaprojects and Contested Information. Transportation Planning and Technology, 30, 49-69. https://doi.org/10.1080/03081060701208050

[9] Cohen, J.P. (2010) The Broader Effects of Transportation Infrastructure: Spatial 
Econometrics and Productivity Approaches. Transportation Research Part E: Logistics and Transportation Review, 46, 317-326. https://doi.org/10.1016/j.tre.2009.11.003

[10] Frick, K.T. (2008) The Cost of the Technological Sublime: Daring Ingenuity and the New San Francisco-Oakland Bay Bridge. In: Flyvbjerg, B., et al., Eds., Decision-Making on Mega-Projects: Cost-Benefit Analysis, Planning and Innovation, Edward Elgar Publishing Inc., Northampton, 239. https://doi.org/10.4337/9781848440173.00020

[11] Pereira, A.M. and Pereira, R. (2015) Is All Infrastructure Investment Created Equal? The Case of Portugal. College of William and Mary Department of Economics Working Paper 156.

[12] Altshuler, A.A. and Luberoff, D.E. (2004) Mega-Projects: The Changing Politics of Urban Public Investment. Brookings Institution Press, Washington DC.

[13] Bristow, A.L. and Nellthorp, J. (2000) Transport Project Appraisal in the European Union. Transport Policy, 7, 51-60. https://doi.org/10.1016/S0967-070X(00)00010-X

[14] Samset, K. (2013) Strategic and Tactical Performance of Mega-Projects-Between Successful Failures and Inefficient Successes. In: International Handbook on Mega-Projects, Edward Elgar Publishing, Northampton, 11-33. https://doi.org/10.4337/9781781002308.00008

[15] Spit, T. (1999) Cities and the Assessment of Economic Effects of Infrastructure Development. In: Wever, E., Ed., Cities in Perspective I. Economy, Planning and the Environment, Van Gorcum, Assen, 129-145.

[16] Jonkhoff, W. and Rustenburg, M. (2011) Indirect Effects in European Transport Project Appraisal. In: Infrastructure Productivity Evaluation, Springer, New York, 79-94. https://doi.org/10.1007/978-1-4419-8101-1_6

[17] Boarnet, M.G. (1996) The Direct and Indirect Economic Effects of Transportation Infrastructure. The University of California Transportation Center, University of California, Berkeley.

[18] Lami, I.M. (2014) Evaluation Tools to Support Decision-Making Process Related to European Corridors. In: Analytical Decision-Making Methods for Evaluating Sustainable Transport in European Corridors, Springer International Publishing, Berlin, 85-101. https://doi.org/10.1007/978-3-319-04786-7_6

[19] Oosterhaven, J. and Elhorst, J.P. (2003) Indirect Economic Benefits of Transport Infrastructure Investments. In: Across the Border. Building upon a Quarter Century of Transport Research in the Benelux, De Boeck, Antwerpen, 143-162.

[20] Steg, L. and Gifford, R. (2005) Sustainable Transportation and Quality of Life. Journal of Transport Geography, 13, 59-69. https://doi.org/10.1016/j.jtrangeo.2004.11.003

[21] Pollack, J.B., Fahri, J., Biesenthal, C. and Sankaran, S. (2015) Understanding Megaproject Success beyond the Project Close-Out Stage. Construction Economics and Building, 15, 48-58. https://doi.org/10.5130/AJCEB.v15i3.4611

[22] Meurs, H., van Wee, B., Perdok, J. and Hoogendoorn, S. (2013) Quick-Scan Appraisal Method to Determine Cost-Effectiveness of Traffic and Demand Management Measures. Transportation Research Record: Journal of the Transportation Research Board, 2359, 36-43. https://doi.org/10.3141/2359-05

[23] Buitelaar, E., Witte, P. and Spit, T. (2014) Understanding the Costs and Revenues of Land Development. In: Witte, P., Ed., The Corridor Chronicles: Integrated Perspectives on European Transport Corridor Development, Eburon Academic Publishers, 
Delft, 111-126.

[24] McCutcheon, R. (2001) An Introduction to Employment Creation in Development and Lessons Learned from Employment Creation in Construction. Urban Forum, 12, 263-278. https://doi.org/10.1007/s12132-001-0006-6

[25] Wardman, M. (1988) A Comparison of Revealed Preference and Stated Preference Models of Travel Behaviour. Journal of Transport Economics and Policy, 22, 71-91.

[26] Zamparini, L. and Reggiani, A. (2007) The Value of Travel Time in Passenger and Freight Transport: An Overview. In: Policy Analysis of Transport Networks, Ashgate, Aldershot, 145-162.

[27] Metz, D. (2008) The Myth of Travel Time Saving. Transport Reviews, 28, 321-336. https://doi.org/10.1080/01441640701642348

[28] Bates, J. (2007) History of Demand Modelling. In: Handbook of Transport Modelling, 2nd Edition, Emerald Group Publishing Limited, Bingley, 11-34. https://doi.org/10.1108/9780857245670-002

[29] Van Wee, B. (2009) Self-Selection: A Key to a Better Understanding of Location Choices, Travel Behaviour and Transport Externalities? Transport Reviews, 29, 279-292. https://doi.org/10.1080/01441640902752961

[30] Buliung, R.N., Roorda, M.J. and Remmel, T.K. (2008) Exploring Spatial Variety in Patterns of Activity-Travel Behaviour: Initial Results from the Toronto Travel-Activity Panel Survey (TTAPS). Transportation, 35, 697-722.

https://doi.org/10.1007/s11116-008-9178-4

[31] Rodrigue, J.P., Comtois, C. and Slack, B. (2013) The Geography of Transport Systems. Routledge, Abingdon-on-Thames.

[32] Rietveld, P. and Bruinsma, F. (2012) Is Transport Infrastructure Effective? Transport Infrastructure and Accessibility: Impacts on the Space Economy. Springer Science \& Business Media, Berlin.

[33] Africani, A., Delpiano, R., Drewello, H., Fontanili, A., Huschebeck, M. and Taake, D. (2016) Comparative Analysis of Accessibility for Freight Transport in Corridor Regions: Results of Two Case Studies. In: Integrated Spatial and Transport Infrastructure Development, Springer International Publishing, Berlin, 133-146. https://doi.org/10.1007/978-3-319-15708-5_8

[34] Graham, D.J. (2007) Agglomeration, Productivity and Transport Investment. Journal of Transport Economics and Policy, 41, 317-343.

[35] Leitham, S., McQuaid, R.W. and Nelson, J.D. (2000) The Influence of Transport on Industrial Location Choice: A Stated Preference Experiment. Transportation Research Part A: Policy and Practice, 34, 515-535.

https://doi.org/10.1016/S0965-8564(99)00030-0

[36] Fowkes, A.S., Firmin, P.E., Tweddle, G. and Whiteing, A.E. (2004) How Highly Does the Freight Transport Industry Value Journey Time Reliability—and for What Reasons? International Journal of Logistics: Research and Applications, 7, 33-43. https://doi.org/10.1080/13675560310001619259

[37] Anas, A., Arnott, R. and Small, K.A. (1998) Urban Spatial Structure. Journal of Economic Literature, 36, 1426-1464.

[38] Fujita, M. and Thisse, J.F. (2013) Economics of Agglomeration: Cities, Industrial Location, and Globalization. Cambridge University Press, Cambridge.

[39] Witte, P. and Spit, T. (2014) Sectoral Drawbacks in Transport: Towards a New Analytical Framework on European Transport Corridors. In: Analytical Deci- 
sion-Making Methods for Evaluating Sustainable Transport in European Corridors, Springer International Publishing, Berlin, 47-61. https://doi.org/10.1007/978-3-319-04786-7_4

[40] Baum, H.S. (1977) Toward a Post-Industrial Planning Theory. Policy Sciences, 8, 401-421. https://doi.org/10.1007/BF01727407

[41] Sunstein, C.R. (2016) Cost-Benefit Analysis and Arbitrariness Review. https://doi.org/10.2139/ssrn.2752068

[42] Grant-Muller, S.M., Mackie, P., Nellthorp, J. and Pearman, A. (2001) Economic Appraisal of European Transport Projects: The State-of-the-Art Revisited. Transport Reviews, 21, 237-261. https://doi.org/10.1080/01441640119423

[43] Campbell, H.F. and Brown, R.P. (2015) Cost-Benefit Analysis: Financial and Economic Appraisal Using Spreadsheets. Routledge, Abingdon-on-Thames.

[44] Jones, H., Moura, F. and Domingos, T. (2014) Transport Infrastructure Project Evaluation Using Cost-Benefit Analysis. Procedia-Social and Behavioral Sciences, 111, 400-409. https://doi.org/10.1016/j.sbspro.2014.01.073

[45] Lami, I.M. (2014) Analytical Decision-Making Methods for Evaluating Sustainable Transport in European Corridors (Vol. 11). Springer, Berlin. https://doi.org/10.1007/978-3-319-04786-7

[46] Hensher, D.A. and Button, K.J. (2008) Handbook of Transport Modelling. Emerald Group Publishing Limited, Bingley.

[47] Lehtonen, M. (2014) Evaluating Megaprojects: From the "Iron Triangle" to Network Mapping. Evaluation, 20, 278-295. https://doi.org/10.1177/1356389014539868

[48] Fayyad, U., Piatetsky-Shapiro, G. and Smyth, P. (1996) From Data Mining to Knowledge Discovery in Databases. AI Magazine, 17, 37.

[49] Kusayanagi, S. and Niraula, R. (2013) Megaprojects in Asia in the 21st Century. Advice from Those Who've Been There, Done That. 291-312. https://doi.org/10.1061/9780784412381.ch15

[50] Coordinating Ministry for Economic Affairs (2011) Masterplan for Acceleration and Expansion of Indonesia Economic Development.

[51] Notohadiprawiro, T. (1999) Performance of Central Kalimantan Wetland Mega-Project: A Critical Review. International Conference and Workshop on Tropical Peat Swamps Safeguarding a Global Natural Resource, Penang, 27-29 July 1999, 27-29.

[52] Delinom, R., Lubis, R.F., Martosuparno, S., Bakti, H. and Taniguchi, M. (2014) Water-Food Nexus: Impact of Rapid Urbanization on Fishery Production in Jakarta Bay Area, Indonesia. In: AGU Fall Meeting Abstracts, San Francisco, Vol. 1, 0992.

[53] JIC Japan International Consultans for Transportation (2012) Feasibility Study for Promotion of International Infrastructure Projects in FY2011. Study on the High Speed Railway Project (Jakarta-Bandung Section), Republic Indonesia. Final Report, Japan International Consultants for Transportation Co., Ltd., Yachiyo Engineering Co., Ltd., Jakarta.

https://www.jetro.go.jp/jetro/activities/contribution/oda/model_study/infra_system /pdf/h23_result03_en.pdf

[54] Hood, C.P. (2006) Shinkansen: From Bullet Train to Symbol of Modern Japan. Routledge, Abingdon-on-Thames. https://doi.org/10.4324/9780203180389

[55] Smith, R.A. (2014) The Shinkansen-World Leading High-Speed Railway System. Japan Railway \& Transport Review, 64, 38-49. 
[56] Okada, H. (1994) Features and Economic and Social Effects of the Shinkansen. Japan Railway and Transport Review, 3, 9-16.

[57] Murakami, J. and Cervero, R. (2012) High-Speed Rail and Economic Development: Business Agglomerations and Policy Implications (No. UCTC-FR-2012-10). University of California Transportation Center, Berkeley.

[58] Han, J., Hayashi, Y., Jia, P. and Yuan, Q. (2012) Economic Effect of High-Speed Rail: Empirical Analysis of Shinkansen's Impact on Industrial Location. Journal of Transportation Engineering, 138, 1551-1557. https://doi.org/10.1061/(ASCE)TE.1943-5436.0000467

[59] Banister, D. and Berechman, J. (2000) Transport Investment and Economic Development. UCL Press, Taylor and Francis Group, Abingdon-on-Thames.

[60] Banister, D. and Berechman, Y. (2001) Transport Investment and the Promotion on Economic Growth. Journal of Transport Geography, 9, 209-218. https://doi.org/10.1016/S0966-6923(01)00013-8

[61] Lakshmanan, T.R. (2011) The Broader Economic Consequences of Transport Infrastructure Investments. Journal of Transport Geography, 19, 1-12. https://doi.org/10.1016/j.jtrangeo.2010.01.001

[62] Esteves, A.M., Franks, D. and Vanclay, F. (2012) Social Impact Assessment: The State of the Art. Impact Assessment and Project Appraisal, 30, 34-42. https://doi.org/10.1080/14615517.2012.660356

[63] Archibugi, F. (2006) Pitfalls in Planning and Plan-Evaluation. In: Urban and Regional Planning and Development Series, Ashgate, Aldershot, 73-84.

[64] Gunton, T. (2003) Megaprojects and Regional Development: Pathologies in Project Planning. Regional Studies, 37, 505-519. https://doi.org/10.1080/0034340032000089068

[65] Salling, K.B. and Leleur, S. (2015) Accounting for the Inaccuracies in Demand Forecasts and Construction Cost Estimations in Transport Project Evaluation. Transport Policy, 38, 8-18. https://doi.org/10.1016/j.tranpol.2014.11.006

[66] Immers, L.H. and Stada, J.E. (2004) Basics of Transport Economics. Faculty of Engineering, Katholieke Universiteit, Leuven, 6.

[67] Morrison-Saunders, A., Pope, J., Gunn, J.A., Bond, A. and Retief, F. (2014) Strengthening Impact Assessment: A Call for Integration and Focus. Impact Assessment and Project Appraisal, 32, 2-8. https://doi.org/10.1080/14615517.2013.872841

[68] Xu, M., Grant-Muller, S. and Gao, Z. (2015) Evolution and Assessment of Economic Regulatory Policies for Expressway Infrastructure in China. Transport Policy, 41, 42-49. https://doi.org/10.1016/j.tranpol.2015.03.007

[69] Korytárová, J. and Hromádka, V. (2014) The Economic Evaluation of Megaprojects-Social and Economic Impacts. Procedia-Social and Behavioral Sciences, 119, 495-502. https://doi.org/10.1016/j.sbspro.2014.03.055 